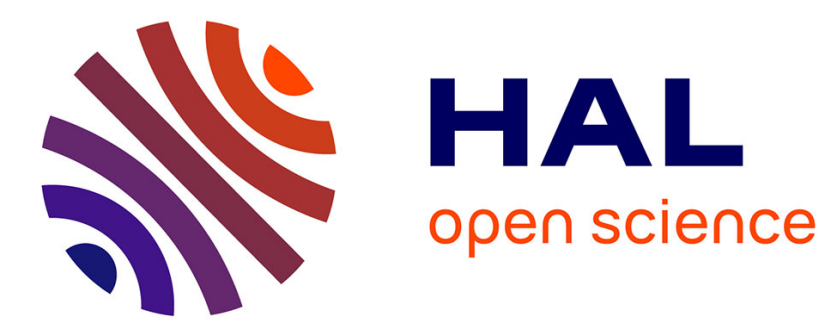

\title{
Ageing with HIV: is the virus or the treatment guilty? Jacqueline Capeau
}

\section{To cite this version:}

Jacqueline Capeau. Ageing with HIV: is the virus or the treatment guilty?. The Lancet HIV, 2021, 8 (4), pp.e182-e183. 10.1016/S2352-3018(20)30337-4 . hal-03190233

\section{HAL Id: hal-03190233 https: / hal.sorbonne-universite.fr/hal-03190233}

Submitted on 6 Apr 2021

HAL is a multi-disciplinary open access archive for the deposit and dissemination of scientific research documents, whether they are published or not. The documents may come from teaching and research institutions in France or abroad, or from public or private research centers.
L'archive ouverte pluridisciplinaire HAL, est destinée au dépôt et à la diffusion de documents scientifiques de niveau recherche, publiés ou non, émanant des établissements d'enseignement et de recherche français ou étrangers, des laboratoires publics ou privés. 


\section{Aging with HIV: is the virus or the treatment guilty?}

Jacqueline Capeau

Sorbonne Université, Faculty of Medicine, Inserm UMR_S938, Saint-Antoine Research Centre, FRM EQU201903007868, ICAN, RHU CARMMA, Paris, France

Jacqueline Capeau, MD, PhD, Faculty of Medicine Sorbonne University, 27 rue Chaligny, 75012 Paris, FRANCE

Email: Jacqueline.capeau@inserm.fr

Due to the availability of antiretroviral drugs (ART) able to efficiency control the virus, people living with HIV (PLWH) are aging and endure, at a higher prevalence than the general population, diverse age-related comorbidities as cardio-metabolic, bone, liver and kidney diseases and some cancers ${ }^{1,2}$. This led to propose that PLWH suffered from premature aging ${ }^{1}$ meaning that their body's age, or biological age, was higher than chronological age.

Biological age can be estimated by performing analysis of epigenetic changes affecting specific DNA methylation sites. In The Lancet HIV, A. Esteban-Cantos and colleagues ${ }^{3}$ used four epigenetic age estimators (Horvath's and Hannum's clocks, GrimAge, PhenoAge), validated in the general population, in $168 \mathrm{PLWH}$ included when ART-naïve in the NEAT001/ANRS143 study, and followed 2 years after initiation of darunavir/ritonavir plus either raltegravir or tenofovir disoproxil fumarate/emtricitabine. PLWH were compared to 44 HIV-negative controls. The authors observed that i) whatever the epigenetic age evaluator, ART-naïve PLWH were biologically older than age-paired controls, ii) epigenetic age was consistently reduced two years after ART initiation, with no difference between the two ART regimens, but iii) remained globally higher than in controls. Therefore, biological age only partially improved with ART. Previous smaller studies already indicated advanced epigenetic age in ART-naïve and also ART-controlled PLWH ${ }^{4}$.

Several important points are pinpointed by this study. The severity of the initial infection increases epigenetic age. The persistent role of HIV, even controlled, could result from a higher size of HIV reservoirs, remaining immune dysfunction, gut dysbiosis, chronic low- 
grade inflammation ${ }^{5}$. Nadir CD4 and CD4/CD8 levels reflect this severity and are recorded. Some recent studies indicate that PLWH suffer enhanced, rather than premature or accelerated, aging, the enhancement occurring during the initial untreated period. Thus, brain aging, assessed by neuroimaging and function, is higher but worsens at the same rate in ART-controlled infected versus non-infected individuals in the COBRA study, stressing for the important beneficial role of $A R T^{6}$.

However, the role of ART is ambivalent. Controlling infection and restoring immunity probably explain the ART beneficial effect on epigenetic aging in the Esteban-Cantos study ${ }^{3}$, but the follow-up was short and the patients young (median 37 years). Some ART classes/molecules have been associated with a higher occurrence of some age-related comorbidities $^{5,7}$. Whether long-term given ART molecules are beneficial or deleterious regarding biological age and associated comorbidities is an important medical issue.

Epigenetic markers differ between the leukocyte subsets. The leukocyte composition was markedly different in the Esteban-Cantos study ${ }^{3}$ between ART-naïve, ART-treated PLWH and controls, as expected. After adjustment on this composition, the epigenetic differences fainted. This point needs to be further addressed.

The authors compare PLWH with a control group for which only age and sex are recorded. This is a concern. It has been shown that using a control group paired for most environmentrelated factors markedly reduced the difference between biological ages estimated by a complex set of parameters ${ }^{8}$ : PLWH remained biologically older $(+12.2$ years) than noninfected paired subjects ( +5.5 years) but both groups markedly differed from very healthy controls (blood donors, -7 years). The proportion of CMV-coinfected patients, not evaluated in the Esteban-Cantos study ${ }^{3}$, is generally markedly higher in PLWH than in the general population. This parameter accounted for the high and similar level of immunosenescent Tcells found in PLWH and paired uninfected subjects in the COBRA study, markedly higher than in healthy blood donors ${ }^{9}$.

The difference in the biological age between PLWH and controls reported in the EstebanCantos study ${ }^{3}$ is +2.5 years before and +1.5 year after ART. This is markedly less than previous studies estimating epigenetic age in the blood ( +5.2 years) and brain ( +7.4 years) of ART-controlled PLWH compared to controls ${ }^{4}$ and also in the COBRA study presented above ${ }^{8}$. 
The NEAT001/ANRS143 study ${ }^{3}$ is a clinical trial, with selected patients, mainly men and Caucasian. Whether the results could apply in the real-life setting, in women and persons from other ethnicities is not known. Thus, recent reports found that some integrase inhibitors induced weight gain in PLWH mainly in women and Black people, while Caucasian men were minimally affected ${ }^{10}$. Moreover, the responsibility of advanced biological age in the worsening of clinical outcomes needs to be addressed in PLWH.

What could be the clinical recommendations regarding evaluation of the epigenetic age in PLWH, especially since the advance is small and has not been associated with clinical outcomes. I don't recommend evaluation at the individual level. However, I recommend its evaluation in clinical studies, especially in aging PLWH. The role of coinfections (CMV, HCV, HBV) and some ART is worth being addressed. Nevertheless, the enhanced epigenetic age in late ART initiators, even if well controlled thereafter, stress for their careful follow-up regarding age-related comorbidities.

\section{Declaration of interests}

$J C$ reports grants paid to the institution from ViiV Healthcare and MSD and personal fees for educational presentations from ViiV Healthcare, MSD, Janssen and Gilead outside the submitted comment.

\section{References}

1. Guaraldi G, Orlando G, Zona S, et al. Premature age-related comorbidities among HIV-infected persons compared with the general population. Clin Infect Dis 2011; 53(11): 1120-6.

2. Schouten J, Wit FW, Stolte IG, et al. Cross-sectional comparison of the prevalence of age-associated comorbidities and their risk factors between HIV-infected and uninfected individuals: the AGEhIV cohort study. Clin Infect Dis 2014; 59(12): 1787-97.

3. Esteban-Cantos A. Epigenetic age accelaration changes two years after antiretroviral therapy initiation in HIV-infected adults: a substudy of the NEAT001/ANRS143 randomised trial. Lancet HIV 2020. 
4. Horvath S, Levine AJ. HIV-1 Infection Accelerates Age According to the Epigenetic Clock. J Infect Dis 2015; 212(10): 1563-73.

5. Lagathu C, Cossarizza A, Bereziat V, Nasi M, Capeau J, Pinti M. Basic science and pathogenesis of ageing with HIV: potential mechanisms and biomarkers. AIDS 2017; 31 Suppl 2: S105-S19.

6. Cole JH, Caan MWA, Underwood J, et al. No Evidence for Accelerated Aging-Related Brain Pathology in Treated Human Immunodeficiency Virus: Longitudinal Neuroimaging Results From the Comorbidity in Relation to AIDS (COBRA) Project. Clin Infect Dis 2018; 66(12): 1899-909.

7. Gelpi M, Afzal S, Fuchs A, et al. Prior exposure to thymidine analogues and didanosine is associated with long-lasting alterations in adipose tissue distribution and cardiovascular risk factors. AIDS 2018.

8. De Francesco D, Wit FW, Burkle A, et al. Do people living with HIV experience greater age advancement than their HIV-negative counterparts? AIDS 2019; 33(2): 259-68.

9. Booiman T, Wit FW, Girigorie AF, et al. Terminal differentiation of $\mathrm{T}$ cells is strongly associated with CMV infection and increased in HIV-positive individuals on ART and lifestyle matched controls. PLoS One 2017; 12(8): e0183357.

10. Koethe JR, Lagathu C, Lake JE, et al. HIV and antiretroviral therapy-related fat alterations. Nat Rev Dis Primers 2020; 6(1): 48. 